OPEN ACCESS

Edited by:

Henri Julius,

Universität Rostock, Germany

Reviewed by:

Ann Bigelow,

St. Francis Xavier University, Canada

Kerstin Uvnäs Moberg,

Swedish University of Agricultural

Sciences, Sweden

*Correspondence:

Victoria Leong

vvec2@cam.ac.uk

Specialty section:

This article was submitted to

Neuroendocrine Science,

a section of the journal

Frontiers in Neuroscience

Received: 02 October 2020

Accepted: 07 December 2020

Published: 05 January 2021

Citation:

Carozza S and Leong V (2021)

The Role of Affectionate Caregiver

Touch in Early Neurodevelopment

and Parent-Infant Interactional

Synchrony.

Front. Neurosci. 14:613378.

doi: 10.3389/fnins.2020.613378

\section{The Role of Affectionate Caregiver Touch in Early Neurodevelopment and Parent-Infant Interactional Synchrony}

\author{
Sofia Carozza ${ }^{1}$ and Victoria Leong ${ }^{2,3 *}$ \\ ${ }^{1}$ Department of Physiology, Development and Neuroscience, Faculty of Biology, University of Cambridge, Cambridge, \\ United Kingdom, ${ }^{2}$ Division of Psychology, Nanyang Technological University, Singapore, Singapore, ${ }^{3}$ Department \\ of Psychology, University of Cambridge, Cambridge, United Kingdom
}

Though rarely included in studies of parent-infant interactions, affectionate touch plays a unique and vital role in infant development. Previous studies in human and rodent models have established that early and consistent affectionate touch from a caregiver confers wide-ranging and holistic benefits for infant psychosocial and neurophysiological development. We begin with an introduction to the neurophysiological pathways for the positive effects of touch. Then, we provide a brief review of how affectionate touch tunes the development of infant somatosensory, autonomic (stress regulation), and immune systems. Affective touch also plays a foundational role in the establishment of social affiliative bonds and early psychosocial behavior. These touch-related bonding effects are known to be mediated primarily by the oxytocin system, but touch also activates mesocorticolimbic dopamine and endogenous opioid systems which aid the development of social cognitive processes such as social learning and reward processing. We conclude by proposing a unique role for affectionate touch as an essential pathway to establishing and maintaining parent-infant interactional synchrony at behavioral and neural levels. The limitations of the current understanding of affectionate touch in infant development point to fruitful avenues for future research.

Keywords: touch, synchrony, social interaction, oxytocin, neurodevelopment, parent-infant

\section{INTRODUCTION}

Early interactions with a parent provide the foundation for infant cognitive and socioemotional development (Raby et al., 2015; Mermelshtine and Barnes, 2016). Affectionate touch, which includes non-noxious light stroking, pressure, and holding, is a unique and essential feature of an infant's interpersonal landscape (Hertenstein, 2002). The sensation of affectionate touch begins in the skin, where a variety of low-threshold mechanoreceptors (LTMRs) respond to different aspects of tactile stimulation. Some classes of LTMRs are myelinated, and their rapid transmission of sensory information enables the brain to discriminate physical stimuli as they touch the skin, while unmyelinated $\mathrm{C}$ afferents transmit information about slow and stable stimuli (McGlone et al., 2014; Olson et al., 2016). Among classes of cutaneous nerves, C-tactile afferents (CTs) appear to be particularly implicated in affectionate touch: light pressure and gentle stroking, especially at skin temperature, results in vigorous CT firing and is perceived as being most enjoyable or 
rewarding (Löken et al., 2009; Ackerley et al., 2014; Pawling et al., 2017). Importantly, children prefer CT-targeted touch throughout development, and when parents are asked to stroke their babies, they naturally do so at a velocity that optimally activates CTs (Croy et al., 2016, 2019). During face-to-face interactions, parent use of affectionate stroking decreases an infant's arousal and increases positive emotionality (PeláezNogueras et al., 1997; Fairhurst et al., 2014). The impact of affectionate touch is far from transient; early interventions involving holding such as kangaroo care, or KMC, lead to positive physiological and psychological outcomes such as regulating stress reactivity and promoting mother-infant bonding, while the deprivation of touch is associated with a range of developmental deficits (Feldman et al., 2002a; Field, 2010b; Moore et al., 2016).

It is hypothesized that affectionate touch-both through CTs (Walker et al., 2017) and other nerve fibers (Uvnäs-Moberg et al., 2015)-achieves many of these effects through the release of the nonapeptide, oxytocin. Gentle stroking of rats increases Fos expression in the oxytocin-producing paraventricular nucleus of the hypothalamus (PVN), and increased plasma oxytocin levels are observed in rats following a wide variety of forms of peripheral sensory stimulation (Stock and Uvnäs-Moberg, 1988; Okabe et al., 2015). In humans, skin-to-skin contact (SSC) and KMC increase peripheral oxytocin levels in both parents and their infant (Vittner et al., 2019; Hardin et al., 2020). It is important to note that this effect is observed only when measured by enzyme immunoassay rather than radioimmunoassay, which may indicate a specific role for active fragments of oxytocin (Uvnäs Moberg et al., 2019); future studies should examine this discrepancy. As oxytocinergic projections from the PVN regulate regions throughout the brain involved in social interaction, pain, stress, and autonomic regulation (Uvnäs-Moberg et al., 2015), the oxytocinergic system is well-positioned to link touch to a wide range of physiological and psychosocial outcomes.

While affectionate touch still remains conspicuously understudied, advances have been made in recent years through both human neuroimaging studies and animal models of maternal care, such as rodent licking and grooming (LG) behavior (Ardiel and Rankin, 2010; Botero et al., 2020). A complete understanding of the role of touch remains elusive, in part because of its dependence on the higher-level social and cultural dimensions of the human person (Ellingsen et al., 2016; Feldman, 2016). However, studies have linked affectionate caregiver touch to infant development across five interrelated domains: the somatosensory system, the autonomic system, immune function, affiliative bonding, and social cognition (Figure 1).

\section{PHYSIOLOGICAL BENEFITS OF AFFECTIONATE CAREGIVER TOUCH}

\section{Somatosensory Tuning}

Affectionate caregiver touch in infancy may aid the maturation of the somatosensory system through experience-dependent plasticity. Most tactile information, including the location and intensity of pleasant touch, is processed in the somatosensory cortex (S1) while the valence and "pleasantness" of touch is detected by the posterior insular cortex (Lindgren et al., 2012; Gordon et al., 2013; Case et al., 2016; Morrison, 2016). The somatosensory processing pathway is highly organized, both serially between regions and somatotopically within regions (Ruben et al., 2001; Björnsdotter et al., 2009; Seelke et al., 2012). While its initial formation is based on genetic factors and sensory feedback from spontaneous movements (Milh et al., 2007; Antón-Bolaños et al., 2019), the system is subsequently refined through experience-dependent mechanisms of structural plasticity (Feldman and Brecht, 2005). In rodents, S1 matures soon after birth, and early-life contact is responsible for the refinement of both its intrinsic connectivity and its cortical and callosal projections (Seelke et al., 2016; Khazipov and Milh, 2018).

Affectionate touch may refine the somatosensory system in humans as well. The fundamental shift from spontaneous to evoked somatosensory activity occurs in the third trimester (Fabrizi et al., 2011), and after birth, the intensity and valence of touch experiences continue to shape somatosensory development (Maitre et al., 2017). In infants, gentle stroking preferentially activates both S1 and the posterior insular cortex; these regions are slightly different from those activated in adults, which may reflect an experience-dependent shift in the localization of affectionate touch processing (Jönsson et al., 2018; Pirazzoli et al., 2019; Tuulari et al., 2019). Lower-level processes of sensation and perception lay the foundation for development of higher-level cognitive functions, therefore early experiences of touch also contribute toward the maturation of neural circuitry for complex cognitive and social function. In fact, infants whose mothers use skin-to-skin touch show greater frontal alpha EEG asymmetry, a pattern of neural activity that reflects emotional processing and cognitive maturation (Hardin et al., 2020). Similarly, pre-term babies who receive caregiver skin contact show faster hemispheric maturation and improved functional connectivity (Scher et al., 2009; Schneider et al., 2012). In fact, an intervention of SSC paired with contingent vocalizations is currently under investigation for its effects on neonatal neurocognitive development (Neel et al., 2019). Conversely, institutionalized children-who often receive inconsistent and low-contact care-tend to exhibit sensory dysregulation, including heightened sensory reactivity, higher rates of sensory processing disorders, and some degree of touch aversion (Dozier et al., 2002; Wilbarger et al., 2010).

\section{Autonomic Regulation}

Affectionate caregiver touch alters multiple aspects of autonomic function, including hypothalamic-pituitary-adrenal (HPA) axis activity and parasympathetic nervous tone. The HPA axis mediates the mammalian stress response. Rats raised with more parental LG show blunted responses to stress and attenuated fear of novelty, due to epigenetic alterations in the expression of hormone receptors in the hippocampus and amygdala (Liu et al., 1997; Caldji et al., 1998; Kundakovic and Champagne, 2015). These effects are specific to touch, as the experimental addition of gentle stroking in the absence of the dam results in the same changes in glucocorticoid receptor expression and corticosteroid secretion (Jutapakdeegul et al., 2003). Consistent with these 


\begin{tabular}{|c|c|c|c|c|c|}
\hline Domain & $\begin{array}{c}\text { Somatosensory } \\
\text { tuning }\end{array}$ & $\begin{array}{l}\text { Autonomic } \\
\text { regulation }\end{array}$ & $\begin{array}{l}\text { Immune } \\
\text { function }\end{array}$ & $\begin{array}{c}\text { Affiliative } \\
\text { bonding }\end{array}$ & $\begin{array}{c}\text { Social } \\
\text { cognition }\end{array}$ \\
\hline \multicolumn{6}{|l|}{$\begin{array}{r}\text { Implicated } \\
\text { regions } \\
\text { and } \\
\text { systems }\end{array}$} \\
\hline $\begin{array}{r}\text { Effects } \\
\text { of touch } \\
\text { in rodents }\end{array}$ & $\begin{array}{l}\text { Increased } \\
\text { connectivity within S1, } \\
\text { refined cortical and } \\
\text { callosal connections }\end{array}$ & $\begin{array}{c}\text { Blunted fear and } \\
\text { stress responses, } \\
\text { epigenetic alterations } \\
\text { to HPA axis }\end{array}$ & $\begin{array}{l}\text { Altered microbiome, } \\
\text { decreased } \\
\text { hippocampal } \\
\text { inflammation }\end{array}$ & $\begin{array}{c}\text { Hypothalamic } \\
\text { oxytocin release, } \\
\text { greater maternal } \\
\text { behaviour later in life }\end{array}$ & $\begin{array}{l}\text { Altered limbic } \\
\text { structure and function, } \\
\text { regulation of dopamine } \\
\text { and opioid systems }\end{array}$ \\
\hline $\begin{array}{r}\text { Related } \\
\text { effects in } \\
\text { humans }\end{array}$ & $\begin{array}{l}\text { Greater hemispheric } \\
\text { maturation and } \\
\text { functional } \\
\text { connectivity }\end{array}$ & $\begin{array}{l}\text { Lower stress } \\
\text { reactivity, heightened } \\
\text { parasympathetic } \\
\text { activity }\end{array}$ & $\begin{array}{l}\text { Decreased risk of } \\
\text { infection, activation of } \\
\text { natural killer cells }\end{array}$ & $\begin{array}{l}\text { Enhanced maternal } \\
\text { interactions, } \\
\text { strengthened } \\
\text { mother-infant bond }\end{array}$ & $\begin{array}{l}\text { Maturation of social } \\
\text { brain, regulation of } \\
\text { dopamine release and } \\
\text { opioid receptor } \\
\text { distribution }\end{array}$ \\
\hline $\begin{array}{r}\text { Possible } \\
\text { developmental } \\
\text { outcomes }\end{array}$ & $\begin{array}{l}\text { Improved sensory } \\
\text { processing and } \\
\text { cognitive function }\end{array}$ & $\begin{array}{l}\text { Adaptive regulation } \\
\text { of stress and } \\
\text { arousal }\end{array}$ & $\begin{array}{l}\text { Lower risk of } \\
\text { mental and } \\
\text { physical illness }\end{array}$ & $\begin{array}{l}\text { Development of } \\
\text { social behaviour and } \\
\text { secure attachment }\end{array}$ & $\begin{array}{l}\text { Regulation of } \\
\text { reward-seeking } \\
\text { behaviour and } \\
\text { enhanced learning }\end{array}$ \\
\hline
\end{tabular}

FIGURE 1 | Physiological and psychological benefits of early-life caregiver touch.

findings, maternal touch-both during free play and $\mathrm{KMC}-$ decreases an infant's physiological stress reactivity (Feldman et al., 2010; Hardin et al., 2020). There appears to be a sensitive period for this effect around the time of birth, as SSC between a mother and her neonate decreases salivary cortisol most when it takes place immediately after birth, and lower stress reactivity in infants is observed even a year later. This touch-mediated effect is hypothesized to be an innate way of reducing the infant's "stress of being born" (Bystrova et al., 2007; Takahashi et al., 2011).

Touch likely achieves stress regulation through oxytocin release in the hypothalamus (Smith and Wang, 2014). Oxytocinergic projections from the PVN to regulatory regions in the brainstem, such as the nucleus of the solitary tract, reduce the activity of noradrenergic neurons and thereby upregulate parasympathetic nervous function (Uvnäs-Moberg et al., 2015). This is supported by the broad range of autonomic changes, beyond HPA activity, that are associated with touch. Throughout infancy, both maternal and paternal touch triggers cardiac deceleration, but only when it involves stroking at speeds that optimally activate CTs (Aguirre et al., 2019; Manzotti et al., 2019; Van Puyvelde et al., 2019). Similarly, neonatal SSC promotes heart rate stabilization and arousal regulation, as well as greater and more rapid weight gain (Feldman et al., 2002b; Cong et al., 2012; Samra et al., 2013). These effects are consistent with increased vagal tone, which modulates heart rate and the gut-brain axis (Yuan and Silberstein, 2016). In fact, there is evidence that stimulation of pressure receptors in the skin increases vagal activity, and that infant vagal activity increases during mother-child interactions (Field and Diego, 2008). Thus, an absence of caregiver touch could also lead to adverse mental and physical outcomes through decreased vagal tone (Thayer and Sternberg, 2006) (in parallel with the HPA effects described previously). In line with this explanation, the infants of depressed mothers-who use less affectionate touch-fail to show an increase in vagal tone over time and often exhibit developmental delays (Field et al., 1995; Herrera et al., 2004; Aoyagi and Tsuchiya, 2019; Mantis et al., 2019).

\section{Immune Function}

A lack of early life-care, which includes touch deprivation, can lead to immune dysregulation. In rats, early isolation alters gut microbiota and raises levels of inflammatory molecules in the hippocampus, indicators of immune dysfunction that are linked to anxiety-like behaviors (Dunphy-Doherty et al., 2018). Children with a history of institutionalization experience a higher risk of intestinal and respiratory infections, as well as skin disorders (Rutter et al., 1998). While the deprivation of touch has yet to be studied in human immune development, childhood adversity is linked to elevated inflammation, T-cell proliferation, and impoverished cellular immune function (Fagundes et al., 2013), and greatly increases risk of physical and mental illness (Anda et al., 2006).

Several human studies link affectionate caregiver touch to positive immunological outcomes. The use of KMC decreases a neonate's risk of severe infections, as well as a variety of other illnesses (Charpak et al., 2001; Boundy et al., 2016). The use of massage increases an infant's proportion of active natural killer cells, although other immunological markers are unaffected (Ang et al., 2012). As microbiota are a critical component of the immune system that remains underdeveloped at birth, one possibility is that touch enhances infant immune function through the transferal of bacteria from the mother's skin (Groer et al., 2015). However, given that massage leads to positive immunological outcomes in a range of populations (Field, 2010b), it is more likely that touch could act through a central neuroendocrine mechanism such as oxytocin release. 
Oxytocin itself plays a critical role in the regulation of the immune system, and has been implicated in the development of T-cells, the suppression of inflammatory cytokines, and wound healing, among other effects (Li et al., 2017; Uvnäs Moberg et al., 2019). While some immunological effects may be achieved through the activation of oxytocin receptors in peripheral organs, more directly, parvocellular neurons in the PVN and supraoptic nucleus have been shown to modulate inflammatory pain by releasing oxytocin in the nuclei of the brainstem and spinal cord (Eliava et al., 2016). As inflammatory cascades have been linked to the pathogenesis or prognosis of an increasing number of common chronic conditions (Bennett et al., 2018), oxytocinergic regulation of the immune system in general and inflammation in particular might provide one possible biological link between early-life touch and long-term health.

\section{PSYCHOSOCIAL BENEFITS OF AFFECTIONATE CAREGIVER TOUCH}

\section{Affiliative Bonding}

Touch may contribute to the genesis of attachment between parent and infant through the action of oxytocin. In rats, gentle stroking increases Fos expression in the oxytocin-producing PVN, and maternal LG induces region-specific increases in oxytocin receptor expression (Francis et al., 2001; Okabe et al., 2015). While rodents do not form attachments as such, SSC with the dam-together with her olfactory cuesare signals of maternal care, and rats deprived of tactile and olfactory stimulation in infancy show impaired maternal behavior themselves in later life (Melo et al., 2006; Kojima et al., 2012). Both SSC and KMC appear to increase peripheral oxytocin levels in human infants, when measured with enzyme immunoassay (Vittner et al., 2018; Hardin et al., 2020). Repeated stimulation of oxytocin release in infants, and its attendant positive effects on autonomic function, may over time lead to a conditioned oxytocinergic response to maternal cues (UvnäsMoberg et al., 2015). Patterns of maternal engagement are also associated with different patterns of oxytocin receptor methylation in infants (Krol et al., 2019), which could modulate the development of infant social behavior (Gordon et al., 2011; Markova, 2018; Xu et al., 2019).

Moreover, affectionate touch is bidirectionally related to parent-infant bonding. In humans, mothers who perform KMC demonstrate heightened sensitivity toward their infant, as well as increased chances of a successful and long first breastfeeding (Tessier et al., 1998; Karimi et al., 2019). Breastfeeding, both through stimulation of sensory receptors in the skin and through the suckling stimulus, results in pulsatile oxytocin release in the mother that increases patterns of social interaction and attenuates pain and stress (UvnäsMoberg et al., 2020). Oxytocin increases parental responsiveness, as well as maternal milk production and consequent breastfeeding (Feldman and Eidelman, 2003; Vittner et al., 2018). In cases of maternal depression, mothers show difficulties in breastfeeding, blunted oxytocin release, and fewer face-to-face interactions with their infants, who are in turn at higher risk of insecure attachment (Lovejoy et al., 2000;
Toth et al., 2009; Field, 2010a; Stuebe et al., 2013). As the motherchild bond is a strong antecedent of the child's socio-emotional and cognitive development (Stams et al., 2002), contributions to affiliative bonding would be an important role for touch in infant development.

The parent-infant bond, in turn, appears to promote the effectiveness of affectionate touch. For instance, 9-month-old infants show greater parasympathetic responses to CT-targeted (stroking at $3 \mathrm{~cm} / \mathrm{s}$ ) in the presence of their parents (Aguirre et al., 2019). Furthermore, when 6-8-month-old infants are gently stroked, they prefer to watch their mother receive synchronous touch over asynchronous touch, but do not show such a preference when gazing at strangers (Maister et al., 2020). Thus, an infant's experience of affectionate touch appears to be bidirectionally related to the parent-infant bond.

\section{Social Cognition: Social Learning and Reward Processing}

A growing body of evidence links caregiver touch to social cognition and function. In young rodents and infant macaque monkeys, early handling and stroking is positively associated with later social learning (Lévy et al., 2003; van Hasselt et al., 2012; Simpson et al., 2019). In humans, children who receive more frequent maternal touch during play show a greater social orientation, or relative interest in faces compared with other objects (Reece et al., 2016). Finally, gentle caregiver strokingbut not other forms of touch-enables 4-month-old infants to recognize faces with an averted gaze, though they typically attend only to faces with a direct gaze (Della Longa et al., 2019). These changes may be mediated by the maturation of the social brain, as frequent maternal touch is associated with greater activity and connectivity of cortical regions implicated in social processing (Brauer et al., 2016).

Rats that experience less LG show suppressed synaptic plasticity and intrinsic excitability in the dorsal hippocampus, and heightened plasticity and excitability in the ventral hippocampus; these changes are related to anxiety-like behaviors (Nguyen et al., 2015). Conversely, early tactile stimulation in rodents triggers dendritic changes that increase the connectivity of the prefrontal cortex and amygdala, differences which are linked to heightened performance on learning tasks (Richards et al., 2012). Though comparable studies have not yet been conducted in humans, in general, parent-infant synchronous interactions have been identified as a key factor in the formation of reward circuitry (Feldman, 2017).

Early experiences of touch also regulate motivational salience through changes to the mesocorticolimbic dopamine and endogenous opioid systems. Within the central nervous system, dopamine release can be associated with both positive (e.g., motivational salience) and negative (e.g., stress response) effects (Trainor, 2011), but given the positive valence of its psychosocial context, affectionate caregiver touch likely activates the prior pathway. Maternal LG triggers a lasting increase in the number of dopaminergic neurons in the ventral tegmental area, particularly in nuclei connected to reward-related areas such as the ventral striatum and the amygdala (Peña et al., 2014). 
Furthermore, developmentally isolated rats show region-specific changes in dopamine turnover, while rats that receive more handling or grooming show heightened dopamine release in response to natural stimuli and blunted sensitivity to stress or psychostimulants (Heidbreder et al., 2000; Brake et al., 2004). Several studies in humans parallel these findings: pleasant touch triggers dopamine release, while less early-life care is associated with greater dopamine release in response to stress (Pruessner et al., 2004; Field et al., 2005). With regard to the opioid system, neonatal handling of rodents increases the expression of $\mu$ opioid receptors (MOR) in reward-related areas (Kiosterakis et al., 2009). Similarly, pleasant social touch increases the availability of MOR in human adults in the thalamus, striatum, and frontal, cingulate, and insular cortices (Nummenmaa et al., 2016). Therefore, affectionate touch appears to promote the development of neural circuits involved in social forms of learning, as well as motivation and reward processing.

\section{A ROLE FOR TOUCH IN PARENT-INFANT INTERACTIONAL SYNCHRONY}

Finally, affectionate touch may provide a unique and essential path to achieving synchrony during parent-infant interactions. Synchrony is the interpersonal coordination of behavioral and neurophysiological rhythms, a normative early-life experience that advances sensory processing, potentiates learning, regulates emotions and arousal, and promotes a stable attachment bond between the infant and her caregiver (Harrist and Waugh, 2002; Beebe et al., 2010; Wass et al., 2020). To facilitate synchrony, parents are primed to express a range of behaviors from the time of their infant's birth, including infant directed speech, gaze, positive affect, and touch (Feldman, 2012). Most developmental research has focused on the vocal, visual, and affective modalities, because synchrony between humans can be established in the absence of physical contact (Feldman et al., 2011). However, SSC between parents and their neonate has been shown to increase the quantity and coordination of vocal and tactile interactions (Velandia et al., 2010). Here, we elaborate on two potential ways in which touch may contribute to achieving and maintaining parent-infant synchrony.

\section{Touch in Parent-Infant Communicative Rhythms}

Touch may convey information that is necessary for the coordination of communicative rhythms between parent and infant. Previous research has found that mothers typically direct communicative behaviors toward their infant while the child is quiet but wakeful (Bell, 2020). As caregiver touch tends to provoke a state of calm alertness (Harrison et al., 2000), parents may use touch to ensure that their infants are available and ready to engage in patterns of communication. Continuous interpersonal touch may be more important during interactions with mothers, whose communicative patterns are usually more regular than the short arousing bursts typically used by fathers (Feldman, 2003). On the part of the infant, experiences of affectionate touch appear to support the development of bodily self-awareness, which in turn permits bodily attunement with their mothers (Montirosso and McGlone, 2020). Touch may perform this role by facilitating the coordination of sensory processing across modalities: in a recent study, infants detected and showed a preference for synchronous visuo-tactile stimuli over asynchronous stimuli while experiencing CT-targeted gentle stroking, but not during other touch (Della Longa et al., 2020). As interactional synchrony requires awareness of self and other, and takes place through coupled auditory, tactile, and visual signaling, affectionate touch may be a critical precursor to the infant's detection of and participation in communicative rhythms.

\section{Touch in Parent-Infant Neural Synchrony}

Touch may mediate the interpersonal coordination of neural activity. Specifically, parental social ostensive cues (typically gaze and speech, but also touch) are hypothesized to reset the phase of ongoing neural oscillations in an infant's neocortex (Wass et al., 2020). This entrains the infant to the ongoing pattern of communication, and also aligns the oscillatory phases of parent and infant neural activity for optimal mutual receptivity. In this way, interpersonal social behaviors such as touch could trigger the synchronization of neural activity with concomitant benefits for communication and learning. A range of evidence supports this proposal along the visual and auditory modalities; both direct gaze and infant-directed speech generate unique patterns of cortical activity in infants (Zhang et al., 2011; Urakawa et al., 2015), and direct gaze produces temporally fine-grained neural entrainment between adults and infants (Leong et al., 2017). Maternal vocal and facial expression of positive emotion also increases parent-infant neural coupling more than negative affect (Santamaria et al., 2020). More broadly, mothers and their infants exhibit neural coupling during synchronous interactions, particularly in areas of the frontal cortex (Reindl et al., 2018; Nguyen et al., 2020). In adults, interpersonal touch such as hand holding enhances neural synchrony (Goldstein et al., 2018). While touch has yet to be isolated in studies of parent-infant neural synchrony, it appears probable that, like the ostensive cues of gaze and speech, touch leads to the phase reset and entrainment of neural oscillations.

\section{CONCLUSION AND FUTURE DIRECTIONS}

Experiences of affectionate touch, mediated by the CT system, are an essential component of parent-infant interactions. Affectionate touch appears to promote an infant's somatosensory system development, autonomic regulation, parent-infant bonding and social development, reward processing and learning, and immune function. Future research should seek to clarify the neurobiological mechanisms involved in early experiences of affectionate touch, including the role of myelinated and unmyelinated sensory fibers and oxytocin signaling pathways in mediating the observed effects.

Affectionate touch may be particularly important for synchronous interactions, which involve the temporal coordination of behavior and physiology. Specifically, SSC, 
through afferent stimulation of nerves from the skin, may have a role in mutual synchronization of maternal and neonatal behaviors and neurophysiology, working in tandem with other important early social cues in the visual (e.g., eye contact) and auditory (e.g., infant-directed speech) sensory domains. Yet up until now, very little research on parent-infant synchrony has included assessments of touch, affectionate or otherwise. However, advances in naturalistic methods for parent-infant dyadic brain imaging (Georgieva et al., 2020; Noreika et al., 2020) now permit the fine-grained examination of complex social behavior involving multiple sensory modalities and their neural substrates (Neale et al., 2018). Therefore, the incorporation of affectionate touch as a key mechanism influencing bio-behavioral synchrony could provide a fruitful avenue for future research on parent-infant interactions.

Future research should also seek to clarify the relationship between affectionate touch and relevant parent and infant characteristics. More broadly, parent-infant interactions involving touch may vary based on the personality and temperament of the partners (Mammen et al., 2016; Beebe and Lachmann, 2017). Similarly, both touch and oxytocin alter brain activity in different ways depending on the relational context (Ellingsen et al., 2016; Baettig et al., 2019), which highlights the importance of including measures of attachment in studies of affectionate touch. Furthermore, a wide range of developmental disorders, including autism, have been bidirectionally linked to differences in touch interactions in infancy (Feldman et al., 2004; Cascio, 2010; Van keer et al., 2019; Provenzi et al., 2020). For example, in autism, atypical touch behavior is implicated as both a predictor of severity (e.g., children who show heightened tactile responsivity later develop greater autistic

\section{REFERENCES}

Ackerley, R., Backlund Wasling, H., Liljencrantz, J., Olausson, H., Johnson, R. D., and Wessberg, J. (2014). Human C-tactile afferents are tuned to the temperature of a skin-stroking caress. J. Neurosci. 34, 2879-2883. doi: 10.1523/JNEUROSCI. 2847-13.2014

Aguirre, M., Couderc, A., Epinat-Duclos, J., and Mascaro, O. (2019). Infants discriminate the source of social touch at stroking speeds eliciting maximal firing rates in CT-fibers. Dev. Cogn. Neurosci. 36:100639. doi: 10.1016/j.dcn. 2019.100639

Anda, R. F., Felitti, V. J., Bremner, J. D., Walker, J. D., Whitfield, C., Perry, B. D., et al. (2006). The enduring effects of abuse and related adverse experiences in childhood: A convergence of evidence from neurobiology and epidemiology. Eur. Arch. Psych. Clin. Neurosci. 256, 174-186. doi: 10.1007/s00406-0050624-4

Ang, J. Y., Lua, J. L., Mathur, A., Thomas, R., Asmar, B. I., Savasan, S., et al. (2012). A randomized placebo-controlled trial of massage therapy on the immune system of preterm infants. Pediatrics 130, e1549-e1558. doi: 10.1542/peds.2012-0196

Antón-Bolaños, N., Sempere-Ferràndez, A., Guillamón-Vivancos, T., Martini, F. J., Pérez-Saiz, L., Gezelius, H., et al. (2019). Prenatal activity from thalamic neurons governs the emergence of functional cortical maps in mice. Science 364, 987-990. doi: 10.03.18/Manuscript_Anton-Bolaños

Aoyagi, S. S., and Tsuchiya, K. J. (2019). Does maternal postpartum depression affect children's developmental outcomes? J. Obstet. Gynaecol. Res. 45, 1809 1820. doi: 10.1111/jog. 14064

Ardiel, E. L., and Rankin, C. H. (2010). The importance of touch in development. Paediatr. Child Health 15, 153-156. doi: 10.1093/pch/15.3.153 behaviors) and well as a potential compensatory mechanism (e.g., mothers of children with autism use more and longer-lasting physical proximity and touch to upregulate social engagement) (Doussard-Roosevelt et al., 2003; Saint-Georges et al., 2011; Mammen et al., 2015). These individual differences in early social sensory behavior could inform the development of sociometric markers for neuropsychiatric disorders in development (Leong and Schilbach, 2019). Finally, mothers touch their male and female infants differently, and a number of sex differences have been found in infant somatosensory processing, including in responsivity to SSC based on both the infant's sex and that of the parent (Velandia et al., 2012; Fausto-Sterling et al., 2015; Walker et al., 2018). Therefore, measures of cognition, personality and temperament, attachment, developmental status, and sex should be incorporated in future studies of caregiver touch and its role in parent-infant interactional synchrony.

\section{AUTHOR CONTRIBUTIONS}

SC and VL wrote the manuscript. Both authors contributed to the article and approved the submitted version.

\section{FUNDING}

This research was funded by a Marshall Scholarship to SC, an ESRC Transforming Social Sciences grant to VL (ES/N006461/1), a Nanyang Technological University grant to VL (M4081585.SS0), and Ministry of Education (Singapore) Tier 1 grants to VL (M4012105.SS0 and M4011750.SS0).

Baettig, L., Baeumelt, A., Ernst, J., Boeker, H., Grimm, S., and Richter, A. (2019). The awareness of the scared - context dependent influence of oxytocin on brain function. Brain Imag. Behav. 14, 2073-2083. doi: 10.1007/s11682-019-00143-2

Beebe, B., and Lachmann, F. (2017). Maternal Self-Critical and Dependent Personality Styles and Mother-Infant Communication. J. Am. Psychoanal. Assoc. 65, 491-508. doi: 10.1177/0003065117709004

Beebe, B., Jaffe, J., Markese, S., Buck, K. A., Chen, H., Cohen, P., et al. (2010). The origins of 12-month attachment: A microanalysis of 4-month motherinfant interaction. Attach. Hum. Dev. 12, 3-141. doi: 10.1080/1461673090333 8985

Bell, M. A. (2020). Mother-child behavioral and physiological synchrony. Advances in Child Development and Behavior, 163-188. doi: 10.1016/bs.acdb.2020.01.006

Bennett, J. M., Reeves, G., Billman, G. E., and Sturmberg, J. P. (2018). Inflammation-nature's way to efficiently respond to all types of challenges: Implications for understanding and managing "the epidemic" of chronic diseases. Front. Med 5:316. doi: 10.3389/fmed.2018.00316

Björnsdotter, M., Löken, L., Olausson, H., Vallbo, ÅB., and Wessberg, J. (2009). Somatotopic organization of gentle touch processing in the posterior insular cortex. J. Neurosci. 29, 9314-9320. doi: 10.1523/JNEUROSCI.0400-09.2009

Botero, M., Langley, H. A., and Venta, A. (2020). The untenable omission of touch in maternal sensitivity and attachment research. Infant Child Dev. 29:e2159. doi: $10.1002 /$ icd.2159

Boundy, E. O., Dastjerdi, R., Spiegelman, D., Fawzi, W. W., Missmer, S. A., Lieberman, E., et al. (2016). Kangaroo mother care and neonatal outcomes: A meta-analysis. Pediatrics 137:e20152238. doi: 10.1542/peds.2015-2238

Brake, W. G., Zhang, T. Y., Diorio, J., Meaney, M. J., and Gratton, A. (2004). Influence of early postnatal rearing conditions on mesocorticolimbic dopamine 
and behavioural responses to psychostimulants and stressors in adult rats. Eur. J. Neurosci. 19, 1863-1874. doi: 10.1111/j.1460-9568.2004.03286.x

Brauer, J., Xiao, Y., Poulain, T., Friederici, A. D., and Schirmer, A. (2016). Frequency of Maternal Touch Predicts Resting Activity and Connectivity of the Developing Social Brain. Cereb. Cortex 26, 3544-3552. doi: 10.1093/cercor/ bhw137

Bystrova, K., Widström, A.-M., Matthiesen, A.-S., Ransjö-Arvidson, A.-B., WellesNyström, B., Wassberg, C., et al. (2007). Skin-to-skin contact may reduce negative consequences of "the stress of being born": a study on temperature in newborn infants, subjected to different ward routines in St. Petersburg. Acta Paediatr. 92, 320-326. doi: 10.1111/j.1651-2227.2003.tb00553.x

Caldji, C., Tannenbaum, B., Sharma, S., Francis, D. D., Plotsky, P. M., and Meaney, M. J. (1998). Maternal care during infancy regulates the development of neural systems mediating the expression of fearfulness in the rat. Proc. Natl. Acad. Sci. U S A. 95, 5335-5340. doi: 10.1073/pnas.95.9.5335

Cascio, C. J. (2010). Somatosensory processing in neurodevelopmental disorders. J. Neurodev. Disord 2, 62-69. doi: 10.1007/s11689-010-9046-3

Case, L. K., Laubacher, C. M., Olausson, H., Wang, B., Spagnolo, P. A., and Bushnell, M. C. (2016). Encoding of touch intensity but not pleasantness in human primary somatosensory cortex. J. Neurosci. 36, 5850-5860. doi: 10.1523/ JNEUROSCI.1130-15.2016

Charpak, N., Ruiz-Peláez, J. G., De Figueroa, Z., and Charpak, Y. (2001). A randomized, controlled trial of Kangaroo Mother Care: Results of follow-up at 1 year of corrected age. Pediatrics 108, 1072-1079. doi: 10.1542/peds.108.5.1072

Cong, X., Cusson, R. M., Walsh, S., Hussain, N., Ludington-Hoe, S. M., and Zhang, D. (2012). Effects of skin-to-skin contact on autonomic pain responses in preterm infants. J. Pain 13, 636-645. doi: 10.1016/j.jpain.2012.02.008

Croy, I., Luong, A., Triscoli, C., Hofmann, E., Olausson, H., and Sailer, U. (2016). Interpersonal stroking touch is targeted to $\mathrm{C}$ tactile afferent activation. Behav. Brain Res. 297, 37-40. doi: 10.1016/j.bbr.2015.09.038

Croy, I., Sehlstedt, I., Wasling, H. B., Ackerley, R., and Olausson, H. (2019). Gentle touch perception: From early childhood to adolescence. Dev. Cogn. Neurosci. 35, 81-86. doi: 10.1016/j.den.2017.07.009

Della Longa, L., Filippetti, M. L., Dragovic, D., and Farroni, T. (2020). Synchrony of Caresses: Does Affective Touch Help Infants to Detect Body-Related VisualTactile Synchrony? Front. Psychol. 10:2944. doi: 10.3389/fpsyg.2019.02944

Della Longa, L., Gliga, T., and Farroni, T. (2019). Tune to touch: Affective touch enhances learning of face identity in 4-month-old infants. Dev. Cogn. Neurosci. 35, 42-46. doi: 10.1016/j.den.2017.11.002

Doussard-Roosevelt, J. A., Joe, C. M., Bazhenova, O. V., and Porges, S. W. (2003). Mother-child interaction in autistic and nonautistic children: Characteristics of maternal approach behaviors and child social responses. Dev. Psychopathol. 15, 277-295. doi: 10.1017/S0954579403000154

Dozier, M., Higley, E., Albus, K. E., and Nutter, A. (2002). Intervening with foster infants' caregivers: Targeting three critical needs. Infant Ment. Health J. 23, 541-544. doi: 10.1002/imhj.10032

Dunphy-Doherty, F., O'Mahony, S. M., Peterson, V. L., O’Sullivan, O., Crispie, F., Cotter, P. D., et al. (2018). Post-weaning social isolation of rats leads to long-term disruption of the gut microbiota-immune-brain axis. Brain. Behav. Immun. 68, 261-273. doi: 10.1016/j.bbi.2017.10.024

Eliava, M., Melchior, M., Knobloch-Bollmann, H. S., Wahis, J., da Silva, Gouveia, M., et al. (2016). A New Population of Parvocellular Oxytocin Neurons Controlling Magnocellular Neuron Activity and Inflammatory Pain Processing. Neuron 89, 1291-1304. doi: 10.1016/j.neuron.2016.01.041

Ellingsen, D. M., Leknes, S., Løseth, G., Wessberg, J., and Olausson, H. (2016). The neurobiology shaping affective touch: Expectation, motivation, and meaning in the multisensory context. Front. Psychol. 6:1986. doi: 10.3389/fpsyg.2015. 01986

Fabrizi, L., Slater, R., Worley, A., Meek, J., Boyd, S., Olhede, S., et al. (2011). A shift in sensory processing that enables the developing human brain to discriminate touch from pain. Curr. Biol. 21, 1552-1558. doi: 10.1016/j.cub.2011.08.010

Fagundes, C. P., Glaser, R., and Kiecolt-Glaser, J. K. (2013). Stressful early life experiences and immune dysregulation across the lifespan. Brain. Behav. Immun. 27, 8-12. doi: 10.1016/j.bbi.2012.06.014

Fairhurst, M. T., Löken, L. S., and Grossmann, T. (2014). Physiological and Behavioral Responses Reveal 9-Month-Old Infants'. Sens. Pleas. Touch. Psychol. Sci. 25, 1124-1131. doi: 10.1177/0956797614527114
Fausto-Sterling, A., Crews, D., Sung, J., García-Coll, C., and Seifer, R. (2015). Multimodal sex-related differences in infant and in infant-directed maternal behaviors during months three through twelve of development. Dev. Psychol. 51, 1351-1366. doi: 10.1037/dev0000033

Feldman, D. E., and Brecht, M. (2005). Map plasticity in somatosensory cortex. Science 310, 810-815. doi: 10.1126/science. 1115807

Feldman, R. (2003). Infant-mother and infant-father synchrony: The coregulation of positive arousal. Infant Ment. Health J. 24, 1-23. doi: 10.1002/imhj.10041

Feldman, R. (2012). Bio-behavioral Synchrony: A Model for Integrating Biological and Microsocial Behavioral Processes in the Study of Parenting. Parenting 12, 154-164. doi: 10.1080/15295192.2012.683342

Feldman, R. (2016). The neurobiology of mammalian parenting and the biosocial context of human caregiving. Horm. Behav. 77, 3-17. doi: 10.1016/j.yhbeh.2015. 10.001

Feldman, R. (2017). The Neurobiology of Human Attachments. Trends Cogn. Sci. 21, 80-99. doi: 10.1016/j.tics.2016.11.007

Feldman, R., and Eidelman, A. I. (2003). Direct and indirect effects of breast milk on the neurobehavioral and cognitive development of premature infants. Dev. Psychobiol. 43, 109-119. doi: 10.1002/dev.10126

Feldman, R., Eidelman, A. I., Sirota, L., and Weller, A. (2002a). Comparison of skin-to-skin (kangaroo) and traditional care: Parenting outcomes and preterm infant development. Pediatrics 110, 16-26. doi: 10.1542/peds.110.1.16

Feldman, R., Keren, M., Gross-Rozval, O., and Tyano, S. (2004). Mother-child touch patterns in infant feeding disorders: Relation to maternal, child, and environmental factors. J. Am. Acad. Child Adolesc. Psychiatry 43, 1089-1097. doi: 10.1097/01.chi.0000132810.98922.83

Feldman, R., Magori-Cohen, R., Galili, G., Singer, M., and Louzoun, Y. (2011). Mother and infant coordinate heart rhythms through episodes of interaction synchrony. Infant Behav. Dev. 34, 569-577. doi: 10.1016/j.infbeh.2011.06.008

Feldman, R., Singer, M., and Zagoory, O. (2010). Touch attenuates infants' physiological reactivity to stress. Dev. Sci. 13, 271-278. doi: 10.1111/j.14677687.2009.00890.x

Feldman, R., Weller, A., Sirota, L., and Eidelman, A. I. (2002b). Skin-to-Skin contact (Kangaroo care) promotes self-regulation in premature infants: sleepwake cyclicity, arousal modulation, and sustained exploration. Dev. Psychol. 38, 194-207. doi: 10.1037/0012-1649.38.2.194

Field, T. (2010a). Postpartum depression effects on early interactions, parenting, and safety practices: A review. Infant Behav. Dev. 33, 1-6. doi: 10.1016/j.infbeh. 2009.10.005

Field, T. (2010b). Touch for socioemotional and physical well-being: A review. Dev. Rev. 30, 367-383. doi: 10.1016/j.dr.2011.01.001

Field, T., and Diego, M. A. (2008). Vagal activity, early growth and emotional development. Infant Behav. Dev. 31, 361-373. doi: 10.1016/j.infbeh.2007.12.008

Field, T., Hernandez-Reif, M., Diego, M. A., Schanberg, S. M., and Kuhn, C. M. (2005). Cortisol decreases and serotonin and dopamine increase following massage therapy. Int. J. Neurosci. 115, 1397-1413. doi: 10.1080/ 00207450590956459

Field, T., Pickens, J., Fox, N. A., Nawrocki, T., and Gonzalez, J. (1995). Vagal tone in infants of depressed mothers. Dev. Psychopathol. 7, 227-231. doi: 10.1017/ S0954579400006465

Francis, D. D., Champagne, F. C., and Meaney, M. J. (2001). Variations in Maternal Behaviour are Associated with Differences in Oxytocin Receptor Levels in the Rat. J. Neuroendocrinol. 12, 1145-1148. doi: 10.1046/j.1365-2826.2000.00599.x

Georgieva, S., Lester, S., Noreika, V., Yilmaz, M. N., Wass, S., and Leong, V. (2020). Toward the Understanding of Topographical and Spectral Signatures of Infant Movement Artifacts in Naturalistic EEG. Front. Neurosci. 14:352. doi: $10.3389 /$ fnins.2020.00352

Goldstein, P., Weissman-Fogel, I., Dumas, G., and Shamay-Tsoory, S. G. (2018). Brain-to-brain coupling during handholding is associated with pain reduction. Proc. Natl. Acad. Sci. U S A. 115, E2528-E2537. doi: 10.1073/pnas.1703643115

Gordon, I., Martin, C., Feldman, R., and Leckman, J. F. (2011). Oxytocin and social motivation. Dev. Cogn. Neurosci. 1, 471-493. doi: 10.1016/j.den.2011.07.007

Gordon, I., Voos, A. C., Bennett, R. H., Bolling, D. Z., Pelphrey, K. A., and Kaiser, M. D. (2013). Brain mechanisms for processing affective touch. Hum. Brain Mapp. 34, 914-922. doi: 10.1002/hbm.21480

Groer, M. W., Gregory, K. E., Louis-Jacques, A., Thibeau, S., and Walker, W. A. (2015). The very low birth weight infant microbiome and childhood health. 
Birth Defects Res. Part C Embryo Today Rev. 105, 252-264. doi: 10.1002/bdrc. 21115

Hardin, J. S., Jones, N. A., Mize, K. D., and Platt, M. (2020). Parent-Training with Kangaroo Care Impacts Infant Neurophysiological Development \& MotherInfant Neuroendocrine Activity. Infant Behav. Dev. 58:101416. doi: 10.1016/j. infbeh.2019.101416

Harrison, L. L., Williams, A. K., Berbaum, M. L., Stem, J. T., and Leeper, J. (2000). Physiologic and behavioral effects of gentle human touch on preterm infants. Res. Nurs. Heal. 23, 435-446. doi: 10.1002/1098-240X(200012)23

Harrist, A. W., and Waugh, R. M. (2002). Dyadic synchrony: Its structure and function in children's development. Dev. Rev. 22, 555-592. doi: 10.1016/S02732297(02)00500-2

Heidbreder, C. A., Weiss, I. C., Domeney, A. M., Pryce, C., Homberg, J., Hedou, G., et al. (2000). Behavioral, neurochemical and endocrinological characterization of the early social isolation syndrome. Neuroscience 100, 749-768. doi: 10.1016/ s0306-4522(00)00336-5

Herrera, E., Reissland, N., and Shepherd, J. (2004). Maternal touch and maternal child-directed speech: Effects of depressed mood in the postnatal period. J. Affect. Disord. 81, 29-39. doi: 10.1016/j.jad.2003.07.001

Hertenstein, M. J. (2002). Touch: Its Communicative Functions in Infancy. Berlin: Karger Publishers.

Jönsson, E. H., Kotilahti, K., Heiskala, J., Wasling, H. B., Olausson, H., Croy, I., et al. (2018). Affective and non-affective touch evoke differential brain responses in 2-month-old infants. Neuroimage 169, 162-171. doi: 10.1016/j.neuroimage. 2017.12.024

Jutapakdeegul, N., Casalotti, S. O., Govitrapong, P., and Kotchabhakdi, N. (2003). Postnatal Touch Stimulation Acutely Alters Corticosterone Levels and Glucocorticoid Receptor Gene Expression in the Neonatal Rat. Dev. Neurosci. 25, 26-33. doi: $10.1159 / 000071465$

Karimi, F. Z., Sadeghi, R., Maleki-Saghooni, N., and Khadivzadeh, T. (2019). The effect of mother-infant skin to skin contact on success and duration of first breastfeeding: A systematic review and meta-analysis. Taiwan. J. Obstet. Gynecol. 58, 1-9. doi: 10.1016/j.tjog.2018.11.002

Khazipov, R., and Milh, M. (2018). Early patterns of activity in the developing cortex: Focus on the sensorimotor system. Semin. Cell Dev. Biol. 76, 120-129. doi: 10.1016/j.semcdb.2017.09.014

Kiosterakis, G., Stamatakis, A., Diamantopoulou, A., Fameli, M., and Stylianopoulou, F. (2009). Long-term effects of neonatal handling on $\mathrm{Mu}$ opioid receptor levels in the brain of the offspring. Dev. Psychobiol. 51, 439-449. doi: $10.1002 /$ dev.20383

Kojima, S., Stewart, R. A., Demas, G. E., and Alberts, J. R. (2012). Maternal Contact Differentially Modulates Central and Peripheral Oxytocin in Rat Pups During a Brief Regime of Mother-Pup Interaction that Induces a Filial Huddling Preference. J. Neuroendocrinol. 24, 831-840. doi: 10.1111/j.1365-2826.2012. 02280.x

Krol, K. M., Moulder, R. G., Lillard, T. S., Grossmann, T., and Connelly, J. J. (2019). Epigenetic dynamics in infancy and the impact of maternal engagement. Sci. Adv. 5:2019. doi: 10.1126/sciadv.aay0680

Kundakovic, M., and Champagne, F. A. (2015). Early-life experience, Epigenetics, and the developing brain. Neuropsychopharmacology 40, 141-153. doi: 10.1038/ npp. 2014.140

Leong, V., and Schilbach, L. (2019). The promise of two-person neuroscience for developmental psychiatry: Using interaction-based sociometrics to identify disorders of social interaction. Br. J. Psychiatry 24, 1-3. doi: 10.1192/bjp.2019.73

Leong, V., Byrne, E., Clackson, K., Georgieva, S., Lam, S., and Wass, S. (2017). Speaker gaze increases information coupling between infant and adult brains. Proc. Natl. Acad. Sci. U S A. 114, 13290-13295. doi: 10.1073/pnas.1702493114

Lévy, F., Melo, A. I., Galef, B. G., Madden, M., and Fleming, A. S. (2003). Complete maternal deprivation affects social, but not spatial, learning in adult rats. Dev. Psychobiol. 43, 177-191. doi: 10.1002/dev.10131

Li, T., Wang, P., Wang, S. C., and Wang, Y. F. (2017). Approaches mediating oxytocin regulation of the immune system. Front. Immunol. 7:693. doi: 10.3389/ fimmu.2016.00693

Lindgren, L., Westling, G., Brulin, C., Lehtipalo, S., Andersson, M., and Nyberg, L. (2012). Pleasant human touch is represented in pregenual anterior cingulate cortex. Neuroimage 59, 3427-3432. doi: 10.1016/j.neuroimage.2011.11.013

Liu, D., Diorio, J., Tannenbaum, B., Caldji, C., Francis, D. D., Freedman, A., et al. (1997). Maternal care, hippocampal glucocorticoid receptors, and hypothalamic- pituitary-adrenal responses to stress. Science 277, 1659-1662. doi: $10.1126 /$ science.277.5332.1659

Löken, L. S., Wessberg, J., Morrison, I., McGlone, F. P., and Olausson, H. (2009). Coding of pleasant touch by unmyelinated afferents in humans. Nat. Neurosci. 12, 547-548. doi: 10.1038/nn.2312

Lovejoy, M. C., Graczyk, P. A., O’Hare, E., and Neuman, G. (2000). Maternal depression and parenting behavior: A meta-analytic review. Clin. Psychol. Rev. 20, 561-592. doi: 10.1016/S0272-7358(98)00100-7

Maister, L., Hodossy, L., Tsakiris, M., and Shinskey, J. L. (2020). Self or (M)other? Infants' Sensitivity to Bodily Overlap With Their Mother Reflects Their Dyadic Coordination. Child Dev. 91, 1631-1649. doi: 10.1111/cdev.13361

Maitre, N. L., Key, A. P., Chorna, O. D., Slaughter, J. C., Matusz, P. J., Wallace, M. T., et al. (2017). The Dual Nature of Early-Life Experience on Somatosensory Processing in the Human Infant Brain. Curr. Biol. 27, 1048-1054. doi: 10.1016/ j.cub.2017.02.036

Mammen, M. A., Moore, G. A., Scaramella, L. V., Reiss, D., Ganiban, J. M., Shaw, D. S., et al. (2015). Infant avoidance during a tactile task predicts autism spectrum behaviors in toddlerhood. Infant Ment. Health J. 36, 575-587. doi: 10.1002/imhj. 21539

Mammen, M. A., Moore, G. A., Scaramella, L. V., Reiss, D., Shaw, D. S., Leve, L. D., et al. (2016). Infant patterns of reactivity to tactile stimulation during parentchild interaction. Infant Behav. Dev. 44, 121-132. doi: 10.1016/j.infbeh.2016.06. 004

Mantis, I., Mercuri, M., Stack, D. M., and Field, T. (2019). Depressed and nondepressed mothers' touching during social interactions with their infants. Dev. Cogn. Neurosci. 35, 57-65. doi: 10.1016/j.den.2018.01.005

Manzotti, A., Cerritelli, F., Esteves, J. E., Lista, G., Lombardi, E., La Rocca, S., et al. (2019). Dynamic touch reduces physiological arousal in preterm infants: A role for c-tactile afferents? Dev. Cogn. Neurosci. 39, 1878-9293. doi: 10.1016/j.dcn. 2019.100703

Markova, G. (2018). The games infants play: Social games during early motherinfant interactions and their relationship with oxytocin. Front. Psychol. 9:1041. doi: 10.3389/fpsyg.2018.01041

McGlone, F. P., Wessberg, J., and Olausson, H. (2014). Discriminative and Affective Touch: Sensing and Feeling. Neuron 82, 737-755. doi: 10.1016/j.neuron.2014. 05.001

Melo, A. I., Lovic, V., Gonzalez, A., Madden, M., Sinopoli, K., and Fleming, A. S. (2006). Maternal and littermate deprivation disrupts maternal behavior and social-learning of food preference in adulthood: Tactile stimulation, nest odor, and social rearing prevent these effects. Dev. Psychobiol. 48, 209-219. doi: $10.1002 /$ dev. 20130

Mermelshtine, R., and Barnes, J. (2016). Maternal Responsive-didactic Caregiving in Play Interactions with 10-month-olds and Cognitive Development at 18 months. Infant Child Dev. 25, 296-316. doi: 10.1002/icd.1961

Milh, M., Kaminska, A., Huon, C., Lapillonne, A., Ben-Ari, Y., and Khazipov, R. (2007). Rapid cortical oscillations and early motor activity in premature human neonate. Cereb. Cortex 17, 1582-1594. doi: 10.1093/cercor/bhl069

Montirosso, R., and McGlone, F. (2020). The body comes first. Embodied reparation and the co-creation of infant bodily-self. Neurosci. Biobehav. Rev. 113, 77-87. doi: 10.1016/j.neubiorev.2020.03.003

Moore, E. R., Bergman, N., Anderson, G. C., and Medley, N. (2016). Early skin-toskin contact for mothers and their healthy newborn infants. Cochrane Database Syst. Rev. 2016:CD003519. doi: 10.1002/14651858.CD003519.pub4

Morrison, I. (2016). ALE meta-analysis reveals dissociable networks for affective and discriminative aspects of touch. Hum. Brain Mapp. 37, 1308-1320. doi: $10.1002 / \mathrm{hbm} .23103$

Neale, D., Clackson, K., Georgieva, S., Dedetas, H., Scarpate, M., Wass, S., et al. (2018). Toward a Neuroscientific Understanding of Play: A Dimensional Coding Framework for Analyzing Infant-Adult Play Patterns. Front. Psychol. 9:273. doi: 10.3389/fpsyg.2018.00273

Neel, M. L., Yoder, P., Matusz, P. J., Murray, M. M., Miller, A., Burkhardt, S., et al. (2019). Randomized controlled trial protocol to improve multisensory neural processing, language and motor outcomes in preterm infants. BMC Pediatr. 19:81. doi: 10.1186/s12887-019-1455-1

Nguyen, H. B., Bagot, R. C., Diorio, J., Wong, T. P., and Meaney, M. J. (2015). Maternal care differentially affects neuronal excitability and synaptic plasticity in the dorsal and ventral hippocampus. Neuropsychopharmacology 40, 15901599. doi: $10.1038 / \mathrm{npp} .2015 .19$ 
Nguyen, T., Schleihauf, H., Kayhan, E., Matthes, D., Vrtička, P., and Hoehl, S. (2020). The effects of interaction quality on neural synchrony during motherchild problem solving. Cortex 124, 235-249. doi: 10.1016/j.cortex.2019.11.020

Noreika, V., Georgieva, S., Wass, S., and Leong, V. (2020). 14 challenges and their solutions for conducting social neuroscience and longitudinal EEG research with infants. Infant Behav. Dev. 58:101393. doi: 10.1016/j.infbeh.2019.101393

Nummenmaa, L., Tuominen, L., Dunbar, R., Hirvonen, J., Manninen, S., Arponen, E., et al. (2016). Social touch modulates endogenous $\mu$-opioid system activity in humans. Neuroimage 138, 242-247. doi: 10.1016/j.neuroimage.2016.05.063

Okabe, S., Yoshida, M., Takayanagi, Y., and Onaka, T. (2015). Activation of hypothalamic oxytocin neurons following tactile stimuli in rats. Neurosci. Lett. 600, 22-27. doi: 10.1016/j.neulet.2015.05.055

Olson, W., Dong, P., Fleming, M., and Luo, W. (2016). The specification and wiring of mammalian cutaneous low-threshold mechanoreceptors. Wiley Interdisc. Rev. Dev. Biol. 5, 389-404. doi: 10.1002/wdev.229

Pawling, R., Cannon, P. R., McGlone, F. P., and Walker, S. C. (2017). Ctactile afferent stimulating touch carries a positive affective value. PLoS One 12:e0173457. doi: 10.1371/journal.pone.0173457

Peláez-Nogueras, M., Field, T., Gewirtz, J. L., Cigales, M., Gonzalez, A., Sanchez, A., et al. (1997). The effects of systematic stroking versus tickling and poking on infant behavior. J. Appl. Dev. Psychol. 18, 169-178. doi: 10.1016/S0193-3973(97) 90034- 4

Peña, C. J., Neugut, Y. D., Calarco, C. A., and Champagne, F. A. (2014). Effects of maternal care on the development of midbrain dopamine pathways and reward-directed behavior in female offspring. Eur. J. Neurosci. 39, 946-956. doi: 10.1111/ejn.12479

Pirazzoli, L., Lloyd-Fox, S., Braukmann, R., Johnson, M. H., and Gliga, T. (2019). Hand or spoon? Exploring the neural basis of affective touch in 5-month-old infants. Dev. Cogn. Neurosci. 35, 28-35. doi: 10.1016/j.dcn.2018.06.002

Provenzi, L., Rosa, E., Visintin, E., Mascheroni, E., Guida, E., Cavallini, A., et al. (2020). Understanding the role and function of maternal touch in children with neurodevelopmental disabilities. Infant Behav. Dev 58:101420. doi: 10.1016/j. infbeh.2020.101420

Pruessner, J. C., Champagne, F. A., Meaney, M. J., and Dagher, A. (2004). Dopamine Release in Response to A Psychological Stress in Humans and Its Relationship to Early Life Maternal Care: A Positron Emission Tomography Study Using [11C] Raclopride. J. Neurosci. 24, 2825-2831. doi: 10.1523/ JNEUROSCI.3422-03.2004

Raby, K. L., Roisman, G. I., Fraley, R. C., and Simpson, J. A. (2015). The Enduring Predictive Significance of Early Maternal Sensitivity: Social and Academic Competence Through Age 32 Years. Child Dev. 86, 695-708. doi: 10.1111/cdev. 12325

Reece, C., Ebstein, R. P., Cheng, X., Ng, T., and Schirmer, A. (2016). Maternal touch predicts social orienting in young children. Cogn. Dev. 39, 128-140. doi: 10.1016/j.cogdev.2016.05.001

Reindl, V., Gerloff, C., Scharke, W., and Konrad, K. (2018). Brain-to-brain synchrony in parent-child dyads and the relationship with emotion regulation revealed by fNIRS-based hyperscanning. Neuroimage 178, 493-502. doi: 10 . 1016/j.neuroimage.2018.05.060

Richards, S., Mychasiuk, R., Kolb, B., and Gibb, R. (2012). Tactile stimulation during development alters behaviour and neuroanatomical organization of normal rats. Behav. Brain Res. 231, 86-91. doi: 10.1016/j.bbr.2012.02.043

Ruben, J., Schwiemann, J., Deuchert, M., Meyer, R., Krause, T., Curio, G., et al. (2001). Somatotopic Organization of Human Secondary Somatosensory Cortex. Cereb. Cortex 11, 463-473. doi: 10.1093/cercor/11.5.463

Rutter, M., Andersen-Wood, L., Beckett, C., Bredenkamp, D., Castle, J., Dunn, J., et al. (1998). Developmental catch-up, and deficit, following adoption after severe global early privation. J. Child Psychol. Psych. Allied Discip. 39, 465-476. doi: 10.1017/S0021963098002236

Saint-Georges, C., Mahdhaoui, A., Chetouani, M., Cassel, R. S., Laznik, M.-C., Apicella, F., et al. (2011). Do Parents Recognize Autistic Deviant Behavior Long before Diagnosis? Taking into Account Interaction Using Computational Methods. PLoS One 6:e22393. doi: 10.1371/journal.pone.0022393

Samra, N. M., Taweel, A., El, and Cadwell, K. (2013). Effect of Intermittent Kangaroo Mother Care on Weight Gain of Low Birth Weight Neonates With Delayed Weight Gain. J. Perinat. Educ. 22, 194-200. doi: 10.1891/1058-1243. 22.4.194
Santamaria, L., Noreika, V., Georgieva, S., Clackson, K., Wass, S., and Leong, V. (2020). Emotional valence modulates the topology of the parent-infant inter-brain network. Neuroimage 207:116341. doi: 10.1016/j.neuroimage.2019. 116341

Scher, M. S., Ludington-Hoe, S. M., Kaffashi, F., Johnson, M. W., HolditchDavis, D., and Loparo, K. A. (2009). Neurophysiologic assessment of brain maturation after an 8-week trial of skin-to-skin contact on preterm infants. Clin. Neurophysiol. 120, 1812-1818. doi: 10.1016/j.clinph.2009.08.004

Schneider, C., Charpak, N., Ruiz-Peláez, J. G., and Tessier, R. (2012). Cerebral motor function in very premature-at-birth adolescents: A brain stimulation exploration of kangaroo mother care effects. Acta Paediatr. Int. J. Paediatr. 101, 1045-1053. doi: 10.1111/j.1651-2227.2012.02770.x

Seelke, A. M. H., Dooley, J. C., and Krubitzer, L. A. (2012). The emergence of somatotopic maps of the body in s1 in rats: The correspondence between functional and anatomical organization. PLoS One 7:e32322. doi: 10.1371/ journal.pone.0032322

Seelke, A. M. H., Perkeybile, A. M., Grunewald, R., Bales, K. L., and Krubitzer, L. A. (2016). Individual differences in cortical connections of somatosensory cortex are associated with parental rearing style in prairie voles (Microtus ochrogaster). J. Comp. Neurol. 524, 564-577. doi: 10.1002/cne.23837

Simpson, E. A., Sclafani, V., Paukner, A., Kaburu, S. S. K., Suomi, S. J., and Ferrari, P. F. (2019). Handling newborn monkeys alters later exploratory, cognitive, and social behaviors. Dev. Cogn. Neurosci. 35, 12-19. doi: 10.1016/j.dcn.2017.07.010

Smith, A. S., and Wang, Z. (2014). Hypothalamic oxytocin mediates social buffering of the stress response. Biol. Psychiatry 76, 281-288. doi: 10.1016/j. biopsych.2013.09.017

Stams, G.-J. J. M., Juffer, F., and Van Ijzendoorn, M. H. (2002). Maternal Sensitivity, Infant Attachment, and Temperament in Early Childhood Predict Adjustment in Middle Childhood: The Case of Adopted Children and Their Biologically Unrelated Parents. Dev Psychol. 38, 806-821. doi: 10.1037/0012-1649. 38.5.806

Stock, S., and Uvnäs-Moberg, K. (1988). Increased plasma levels of oxytocin in response to afferent electrical stimulation of the sciatic and vagal nerves and in response to touch and pinch in anaesthetized rats. Acta Physiol. Scand. 132, 29-34. doi: 10.1111/j.1748-1716.1988.tb08294.x

Stuebe, A. M., Grewen, K., and Meltzer-Brody, S. (2013). Association between maternal mood and oxytocin response to breastfeeding. J. Women's Heal. 22, 352-361. doi: 10.1089/jwh.2012.3768

Takahashi, Y., Tamakoshi, K., Matsushima, M., and Kawabe, T. (2011). Comparison of salivary cortisol, heart rate, and oxygen saturation between early skin-to-skin contact with different initiation and duration times in healthy, full-term infants. Early Hum. Dev. 87, 151-157. doi: 10.1016/j.earlhumdev.2010.11.012

Tessier, R., Cristo, M., Velez, S., Giron, M., de Calume, Z. F., Ruiz-Peláez, J. G., et al. (1998). Kangaroo mother care and the bonding hypothesis. Pediatrics 102:e17. doi: 10.1542/peds.102.2.e17

Thayer, J. F., and Sternberg, E. (2006). Beyond Heart Rate Variability: Vagal Regulation of Allostatic Systems. Ann. N. Y. Acad. Sci. 1088, 361-372. doi: 10.1196/annals.1366.014

Toth, S. L., Rogosch, F. A., Sturge-Apple, M., and Cicchetti, D. (2009). Maternal depression, children's attachment security, and representational development: An organizational perspective. Child Dev. 80, 192-208. doi: 10.1111/j.14678624.2008.01254.x

Trainor, B. C. (2011). Stress responses and the mesolimbic dopamine system: Social contexts and sex differences. Horm. Behav. 60, 457-469. doi: 10.1016/j.yhbeh. 2011.08.013

Tuulari, J. J., Scheinin, N. M., Lehtola, S., Merisaari, H., Saunavaara, J., Parkkola, R., et al. (2019). Neural correlates of gentle skin stroking in early infancy. Dev. Cogn. Neurosci. 35, 36-41. doi: 10.1016/j.dcn.2017.10.004

Urakawa, S., Takamoto, K., Ishikawa, A., Ono, T., and Nishijo, H. (2015). Selective Medial Prefrontal Cortex Responses During Live Mutual Gaze Interactions in Human Infants: An fNIRS Study. Brain Topogr. 28, 691-701. doi: 10.1007/ s10548-014-0414-2

Uvnäs Moberg, K., Handlin, L., Kendall-Tackett, K., and Petersson, M. (2019). Oxytocin is a principal hormone that exerts part of its effects by active fragments. Med. Hypotheses 133:109394. doi: 10.1016/j.mehy.2019.109394

UvnäsMoberg, K., Ekström-Bergström, A., Buckley, S., Massarotti, C., Pajalic, Z., Luegmair, K., et al. (2020). Maternal plasma levels of oxytocin during 
breastfeeding-A systematic review. PLoS One 15:e0235806. doi: 10.1371/ journal.pone.0235806

Uvnäs-Moberg, K., Handlin, L., and Petersson, M. (2015). Self-soothing behaviors with particular reference to oxytocin release induced by non-noxious sensory stimulation. Front. Psychol. 5:1529. doi: 10.3389/fpsyg.2014.01529

van Hasselt, F. N., Tieskens, J. M., Trezza, V., Krugers, H. J., Vanderschuren, L. J. M. J., and Joëls, M. (2012). Within-litter variation in maternal care received by individual pups correlates with adolescent social play behavior in male rats. Physiol. Behav. 106, 701-706. doi: 10.1016/j.physbeh.2011.12.007

Van keer, I., Ceulemans, E., Bodner, N., Vandesande, S., Van Leeuwen, K., and Maes, B. (2019). Parent-child interaction: A micro-level sequential approach in children with a significant cognitive and motor developmental delay. Res. Dev. Disabil. 85, 172-186. doi: 10.1016/j.ridd.2018.11.008

Van Puyvelde, M., Collette, L., Gorissen, A. S., Pattyn, N., and McGlone, F. (2019). Infants autonomic cardio-respiratory responses to nurturing stroking touch delivered by the mother or the father. Front. Physiol. 10:1117. doi: 10.3389/ fphys.2019.01117

Velandia, M., Matthisen, A.-S., Uvnäs-Moberg, K., and Nissen, E. (2010). Onset of Vocal Interaction Between Parents and Newborns in Skin-to-Skin Contact Immediately After Elective Cesarean Section. Birth 37, 192-201. doi: 10.1111/j. 1523-536X.2010.00406.x

Velandia, M., Uvnäs-Moberg, K., and Nissen, E. (2012). Sex differences in newborn interaction with mother or father during skin-to-skin contact after Caesarean section. Acta Paediatr. Int. J. Paediatr. 101, 360-367. doi: 10.1111/j.1651-2227. 2011.02523.x

Vittner, D., Butler, S., Smith, K., Makris, N., Brownell, E., Samra, H., et al. (2019). Parent Engagement Correlates with Parent and Preterm Infant Oxytocin Release during Skin-to-Skin Contact. Adv. Neonatal Care 19, 73-79. doi: 10. 1097/ANC.0000000000000558

Vittner, D., McGrath, J., Robinson, J., Lawhon, G., Cusson, R. M., Eisenfeld, L., et al. (2018). Increase in Oxytocin From Skin-to-Skin Contact Enhances Development of Parent-Infant Relationship. Biol. Res. Nurs. 20, 54-62. doi: $10.1177 / 1099800417735633$
Walker, S. C., Trotter, P. D., Swaney, W. T., Marshall, A., and McGlone, F. P. (2017). $\mathrm{C}$-tactile afferents: Cutaneous mediators of oxytocin release during affiliative tactile interactions? Neuropeptides 64, 27-38. doi: 10.1016/j.npep.2017.01.001

Walker, S. M., Melbourne, A., O’Reilly, H., Beckmann, J., Eaton-Rosen, Z., Ourselin, S., et al. (2018). Somatosensory function and pain in extremely preterm young adults from the UK EPICure cohort: sex-dependent differences and impact of neonatal surgery. Br. J. Anaesth. 121, 623-635. doi: 10.1016/j.bja. 2018.03.035

Wass, S. V., Whitehorn, M., Marriott Haresign, I., Phillips, E., and Leong, V. (2020). Interpersonal Neural Entrainment during Early Social Interaction. Trends Cogn. Sci. 24, 329-342. doi: 10.1016/j.tics.2020.01.006

Wilbarger, J., Gunnar, M., Schneider, M., and Pollak, S. (2010). Sensory processing in internationally adopted, post-institutionalized children. J. Child Psychol. Psychiatry Allied Discip. 51, 1105-1114. doi: 10.1111/j.1469-7610.2010.02255.x

Xu, L., Becker, B., and Kendrick, K. M. (2019). Oxytocin facilitates social learning by promoting conformity to trusted individuals. Front. Neurosci 13:56. doi: 10.3389/fnins.2019.00056

Yuan, H., and Silberstein, S. D. (2016). Vagus Nerve and Vagus Nerve Stimulation, a Comprehensive Review: Part i. Headache 56, 71-78. doi: 10.1111/head.12647

Zhang, Y., Koerner, T., Miller, S., Grice-Patil, Z., Svec, A., Akbari, D., et al. (2011). Neural coding of formant-exaggerated speech in the infant brain. Dev. Sci. 14, 566-581. doi: 10.1111/j.1467-7687.2010.01004.x

Conflict of Interest: The authors declare that the research was conducted in the absence of any commercial or financial relationships that could be construed as a potential conflict of interest.

Copyright (c) 2021 Carozza and Leong. This is an open-access article distributed under the terms of the Creative Commons Attribution License (CC BY). The use, distribution or reproduction in other forums is permitted, provided the original author(s) and the copyright owner(s) are credited and that the original publication in this journal is cited, in accordance with accepted academic practice. No use, distribution or reproduction is permitted which does not comply with these terms. 


\section{GLOSSARY OF ABBREVIATIONS}

CTs: C-tactile afferents. A class of unmyelinated sensory neurons found in human skin that mediate the sensation of pleasant touch. HPA axis: the hypothalamic-pituitary-adrenal axis. A set of interactions between the hypothalamus, pituitary gland, and adrenal glands that controls the mammalian stress response.

KMC: Kangaroo Mother Care. A method of care for human infants that involves placing the child on the mother's chest for access to breastfeeding and skin-to-skin contact.

LG: licking and grooming. Maternal care behaviors observed in rodents.

LTMRs: low-threshold mechanoreceptors. A class of somatosensory receptors that react to light touch.

PVN: the paraventricular nucleus of the hypothalamus. A region of the hypothalamus that regulates a range of homeostatic functions and contains a large population of oxytocin-secreting neurons.

SSC: skin-to-skin contact. A method of care for human infants that involves placing the naked infant on the mother's bare chest soon after birth.

S1: the primary somatosensory cortex. An area of the cortex in the postcentral gyrus that receives inputs from the thalamus; it is the primary region responsible for processing somatic stimuli. 